\title{
METHOD OF THE FINITE-ELEMENT MODEL FORMATION CONTAINING THE 3D ELEMENTS FOR STRUCTURAL CALCULATIONS OF THE REINFORCED CONCRETE STRUCTURES CONSIDERING THE CRACK OPENING
}

\author{
Sergei N. Nazarenko*, Galina A. Grudcina \\ RUT (MIIT), Moscow, Russia \\ *E-mail of corresponding author: s.nazarenko@mail.ru
}

\section{Resume}

This article presents the 3D computational modeling method for reinforced concrete structures. An example of calculation of the reinforced concrete beam, using the Finite Element Method in SCAD++ following proposed algorithm, is given. Results comparison to the analytical calculation of the model with selected reinforcement is presented. For concrete, the 3D solid Finite Elements are used and the 3D beam elements for reinforcement. The model is formed using AutoCAD and AutoLISP, which creates a text data file in SCAD format for the description of model. In addition, computation of the 3D model of the crossbar with a crack is performed. Crack sizes are set in the stretched zone based on data from initial calculation. Graphic results obtained in SCAD++ are presented.

\section{Article info}

Received 5 May 2020

Accepted 10 August 2020

Online 30 November 2020

\section{Keywords:}

concrete structures, finite element method, $3 \mathrm{D}$ elements, cracks in concrete, $\mathrm{SCAD}++$ AutoCAD, AutoLISP

\section{Introduction}

The reinforced concrete (RC) structures can have various applications in construction, such as beams, slabs, shells, massive structures, often of a complex shape, defined by the architectural features of the designed structure and construction process. The reinforced concrete structures calculation, based on standard approaches, does not define an adequate model for the stress-strain state, both in concrete and in reinforcement due to multiple reasons, such as crack propagation in concrete, complex geometry and structural dimensions, not allowing the use of beam theory.

Currently, engineers use the rod elements for calculations of the reinforced concrete structures, as a creation of volumetric elements and complex shape, is a very difficult and time-consuming process. Appearance of cracks is allowed by standards [1]. However, as shown in results of simulation performed in this article, appearance of even minor cracks noticeably increases stresses in the reinforcement rebars. Such consequences cannot be considered in calculations without using the 3D elements.

Calculation of the crack formation and size of the crack opening is important to ensure the bearing capacity of the reinforcement and durability of the reinforced concrete structures. The paper [1] presents a comparative analysis of the existing SP calculation methods for the normal crack formation, based on a nonlinear deformation model. For simple types of structures, the joint venture allows calculation according to a simplified method (by limiting forces). Usually, an assumption to perform calculations, using simplified methods, is organized in such a way that the obtained results provide a margin of reliability. However, that is not valid in the case of the normal crack opening width analysis, as shown in the article [1].

Remaining within the same normative document, the spread of acceptable crack opening values can exceed $50 \%[1]$.

If one considers problems with reinforcement in a compressed zone and stronger concrete, the discrepancies between the deformation and force approach can increase up to $200-300 \%$ [1].

As a result, it can be concluded that in order to solve the described problem, the development of methodology that allows to determine as accurately as possible the value of crack opening in reinforced concrete structures is needed.

The purpose of this article is to present a method of a complex strength calculation of reinforced concrete elements, allowing to consider the factors mentioned above and to obtain more precise values of the elements stress-strain state, including reinforcement, considering 


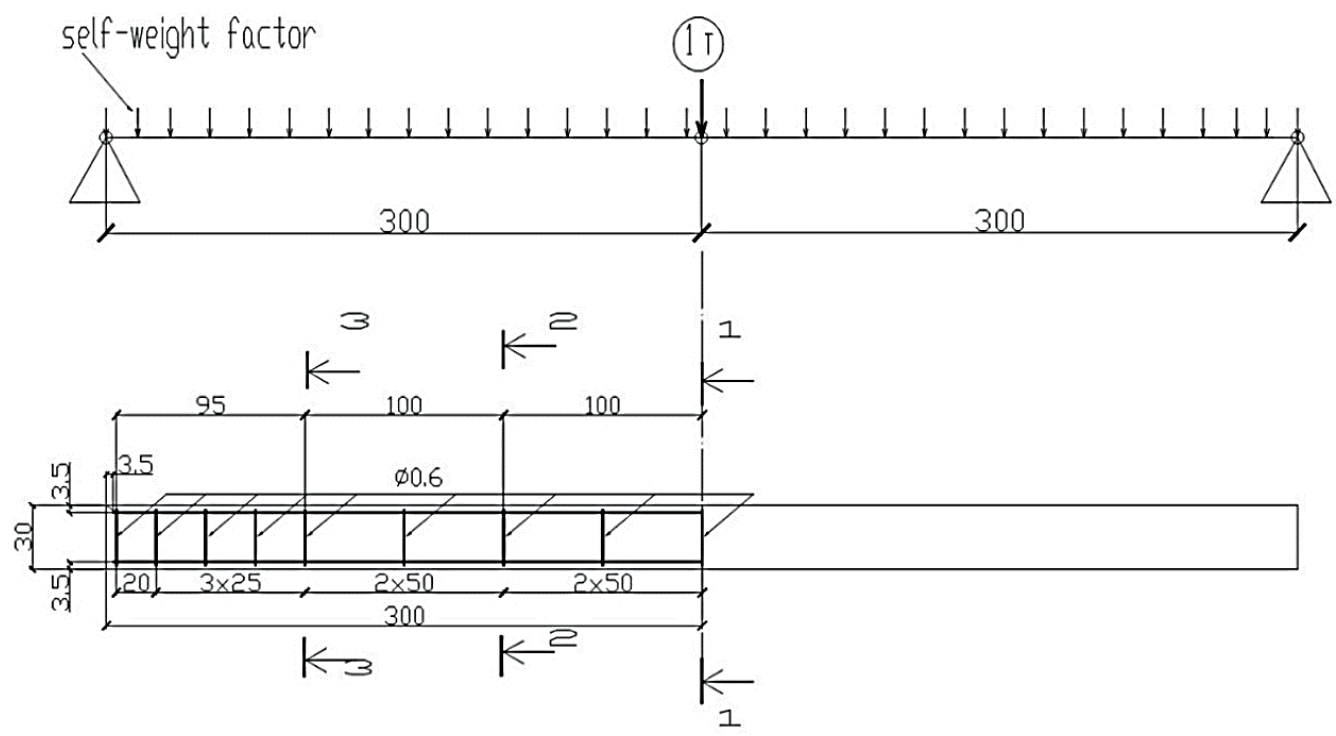

Figure 1 Scheme of the reinforced concrete beam (dimensions in $\mathrm{cm}$ ) loaded with distributed load from the self- weight factor and concentrated load on the symmetry axis

occurrence and opening of cracks. The method is based on application of the 3D solid finite elements with maximum automation of labor-intensive processes of the 3D model creation.

\section{$2 \quad$ Methodology}

To solve the problem of specifying the calculated values of stress-strain state in reinforced concrete structures, it is proposed to define their models as the $3 \mathrm{D}$ objects for the FEM calculation, with use of Solid 3D Finite Elements (FE) for modeling concrete and Beam $\mathrm{FE}$ for modeling reinforcement. The resulting difficulties can be divided into three categories:

1. The large number of the 3D finite elements required to obtain enough accuracy of the FEM calculations when forming the 3D model.

2. The complex geometry of a structure, which causes difficulties in forming input data of the FEM model

3. Difficulties of the model assembling when joining nodes of the 3D FE modeling concrete and Truss FE modeling rebars.

To solve these problems, the following is used:

SCAD FEM complex for strength analysis and solidstate eight-node iso-parametric 3D finite element from SCAD++ library, other possibilities used for solid-state modeling, given in article [2]. SCAD is an integrated system for the finite element structural analysis and design. Software is chosen because of its wide range of finite elements and calculation modes available and, at the same time, the possibility to use the standard documents for reinforcement and cross-section. As a result, the software is well-ranked and widely used in engineering practice [3-11] Multiple comparative results analyses proved calculations accuracy compared to other software: SAP2000 [12], ETABS [13], MIDAS GTS NX [14], Tekla Structures [15-16], PLAXIS [17].
1. SCAD provides data exchange with other programs using:

- universal formats (IFC, CIS/2, DXF, DWG, TXT);

- data formats of Advance Steel, ANSYS, STAAD, Abaqus, Femap, GMSH, NetGen;

- $\quad$ plugins for Revit, ArchiCAD, Tekla.

2. AutoCAD software to define a beam reinforcing frame of RC models, networks in the foundation of solid 3D models and their nodal coordinates using AutoCAD graphic database.

3. Program, developed by S. N. Nazarenko using AutoLISP language, embedded in AutoCAD, which is also described in the article [18], automatically creating a text data file in SCAD format [18-19] for a FE model, consisting of 3D FEs.

This program automatically generates arrays of topology and coordinates for the finite element model, then generates text data file in SCAD format for definition of the 3D model sub-structures. Volumetric sub-structures are then joined together, merging with the core elements in $\mathrm{SCAD}++$ assembly procedure, as well. More details about program realization on AutoLISP for formation of covers are also available in [2, 18-19]. Problems of modeling and calculating massive structures of bridges, supports and other 3D structures, based on their parametric dimensions, were solved by this program. Using this program in conjunction with AutoCAD allows optimizing SCAD 3D modeling of structures and reducing time consumed.

\section{Example}

The developed method is demonstrated using an example of the reinforced concrete beam with rectangular cross-section. It should be mentioned that the proposed method can be used for calculation of the reinforced concrete structures with more complex cross-sections, as well. 



Figure 2 Results of selection of the longitudinal rebars and structural transverse armature of reinforced concrete beam from Figure 1, specified according to the standards (dimensions in $\mathrm{mm}$ )

Table 1 Concrete working conditions ratios

\begin{tabular}{|c|c|c|}
\hline & concrete type: heavy & concrete class: B25 \\
\hline \multicolumn{3}{|c|}{ concrete working conditions ratios } \\
\hline$\gamma_{\mathrm{b} 1}$ & considering long-acting loads & 0.9 \\
\hline$\gamma_{\mathrm{b} 2}$ & considering the nature of the destruction & 1 \\
\hline$\gamma_{\mathrm{b} 3}$ & considering the vertical position when constructing & 1 \\
\hline$\gamma_{\mathrm{b} 5}$ & considering freezing/thawing and negative temperatures & 1 \\
\hline
\end{tabular}

For the girder shown in Figure 1, calculation is done in system SCAD++ for the purpose of the subsequent comparison of results for two models:

The first model: the beam model, results of deflection determination for this model are shown in Figure 3;

The second model: the 3D model formed by solid 3D finite elements used for concrete, which were combined in $\mathrm{SCAD}++$ by means of assembly with beam elements simulating reinforcement. The process of forming the 3D model of the girder is shown in Figures 4-6. Results of its calculation are shown in Figures 7-14.

\section{Standard method}

At the first step, the calculation of the girder is performed and modeling it with the rod elements, using the standard methodology described in SP [20-22].

Selection of reinforcement was carried out by SP 63.13330.2012.

The following parameters were used:

- $\quad$ element type - bendable beam element;

- $\quad$ load case - uniaxial bending;

- maximum reinforcement percentage- $10 \%$.

Longitudinal reinforcement of class A400steel rebars and transverse reinforcement of class A240 steel rebars were used for calculation. Concrete working conditions ratio 1 was applied.

For the concrete, the parameters specified in Table 1 were used.

By iteration and meeting the above conditions, the maximum value of crack opening, equal to $0.388 \mathrm{~mm}$, is obtained.
For the girder shown in Figure 1, the calculation was carried out in the SCAD++ system to compare the results of calculations of two versions model: the beam and 3D.

Next is presented an analysis of the SP recommendations [20-22]. The width of opening of normal cracks is calculated by formula:

$a_{c r c, i}=\varphi_{1} \varphi_{2} \varphi_{3} \psi_{s} \cdot \frac{\sigma_{s}}{E_{s}} l_{s}$.

where:

$\sigma_{s}$-is the stress in a longitudinal rebars in tension in its normal cross-section with a crack from the corresponding external load;

$\psi_{s}$ - the coefficient considering the non-uniform distribution of relative deformations of stretched reinforcement between cracks;

$l_{s}$ - basic (without considering the influence of the rebars surface type) distance between adjacent normal cracks;

$\varphi_{1}$ - coefficient taking into account duration of the load;

$\varphi_{2}$ - coefficient taking into account profile of the longitudinal fitting;

$\varphi_{3}$ - coefficient taking into account nature of the load.

The stress values in the tensioned rebars of the bending elements are determined by the formula:

$\sigma_{s}=\frac{M\left(h_{0}-y_{c}\right)}{I_{\text {red }}} \cdot \alpha_{s l}$

where:

$I_{\text {red }}$ and $y_{c}$ - moment of inertia and height of the compressed zone of the element's reduced cross-section, respectively, defined taking into account the cross-section area only of the compressed zone of concrete, areas of section of the stretched and compressed armature, taking into account 


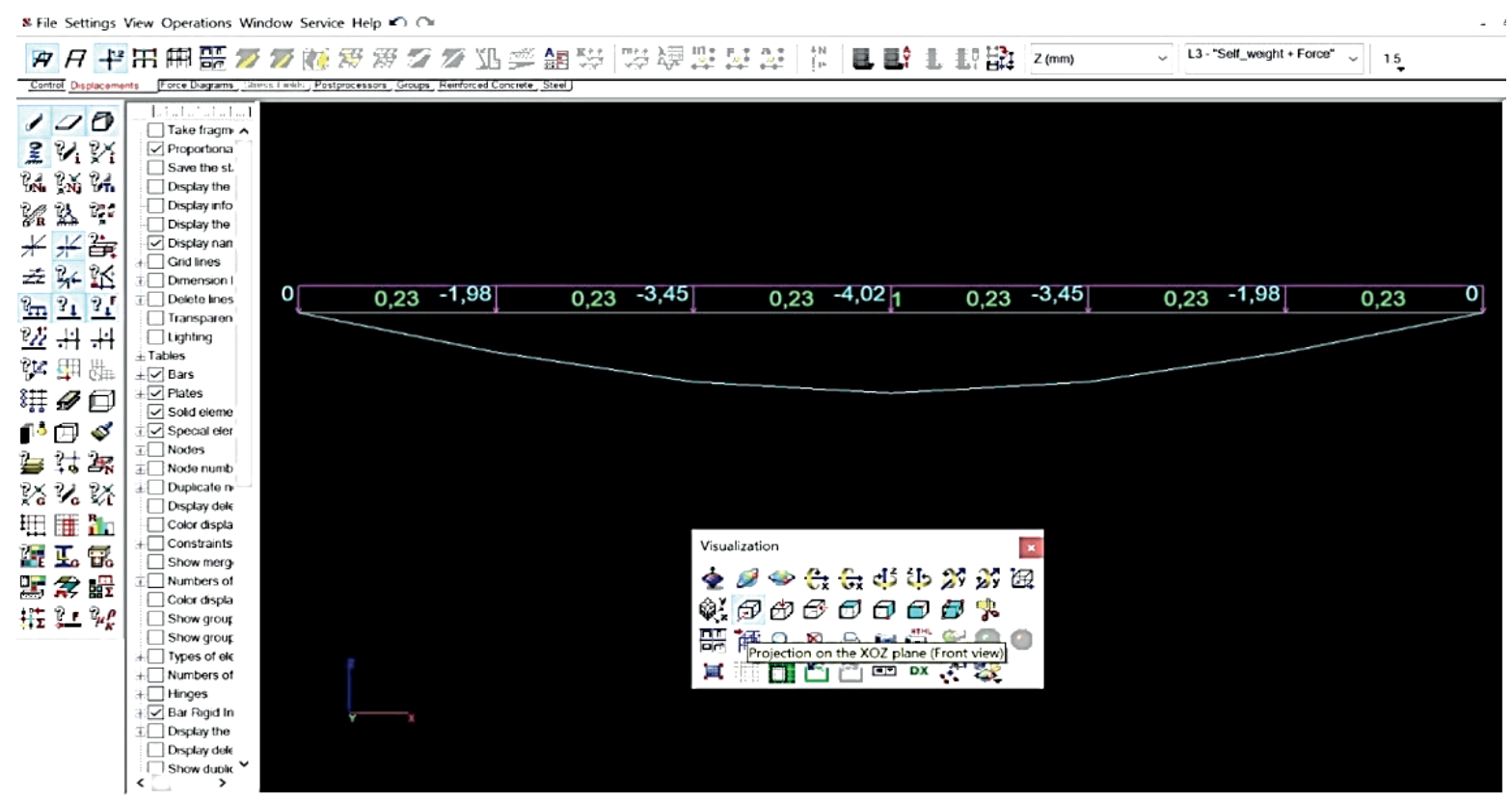

Figure 3 Results of the beam deflection calculation using $S C A D$

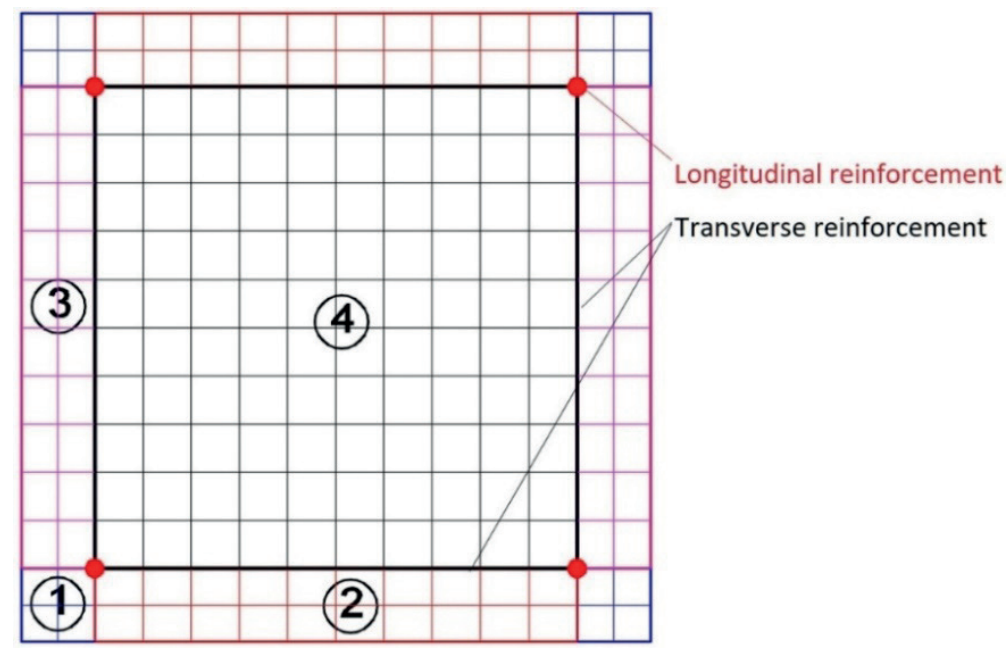

Figure 4 Networks AutoCAD with numbers of separated segments of the RC beam, used to create the $3 D F E$ model

values of factor of reduction of armature to concrete, in corresponding formulas;

$h_{0}$ - operational height;

$y_{c}$ - for bending elements $y_{c}=x$, where $x$ is the height of the compressed concrete zone.

$\alpha_{s l}$ - coefficient of adduction.

According to SP, the following options can be applied:

- The coefficient $\psi_{s}=1-0.8 \frac{\sigma_{s, c r c}}{\sigma_{s}}$. or $\psi_{s}=1-0.8 \frac{M_{c r c}}{M}$

- Crack initiation moment $M_{c r c}=1.3 R_{b t, s e r} W_{r e d}\left(W_{\text {red }}\right.$ defined with or without assuming the reinforcement);

- $\quad$ Stress $\sigma_{s}=\frac{M\left(h_{0}-y_{c}\right)}{I_{\text {red }}} \cdot \alpha_{s l}$ or $=\frac{M}{z_{s} \cdot A_{S}}$

- the distance from the center of gravity of the stretched rebars to the point of application of resulting force in the compressed zone of the element $z_{s}=h_{0}-\frac{x}{3}$ or

$$
z_{s}=0.8 h_{0}
$$

Similarly, $\sigma_{s, c r c}$ - tension in the longitudinal stretched reinforcement in the section with a crack immediately after the formation of normal cracks.

\section{New method}

After obtaining the stress-strain state and cracks opening by the standard method, following are the stages of formation and calculation of the 3D model of a beam with application of the 3D solid FE and crack modeling, using axial symmetry for a beam from Figure 1, what reduces the number of FE twice. We use the AutoCAD software. The cross-section in the middle of the beam is given in Figure 4. For formation of model of the 3D FE, it is necessary 


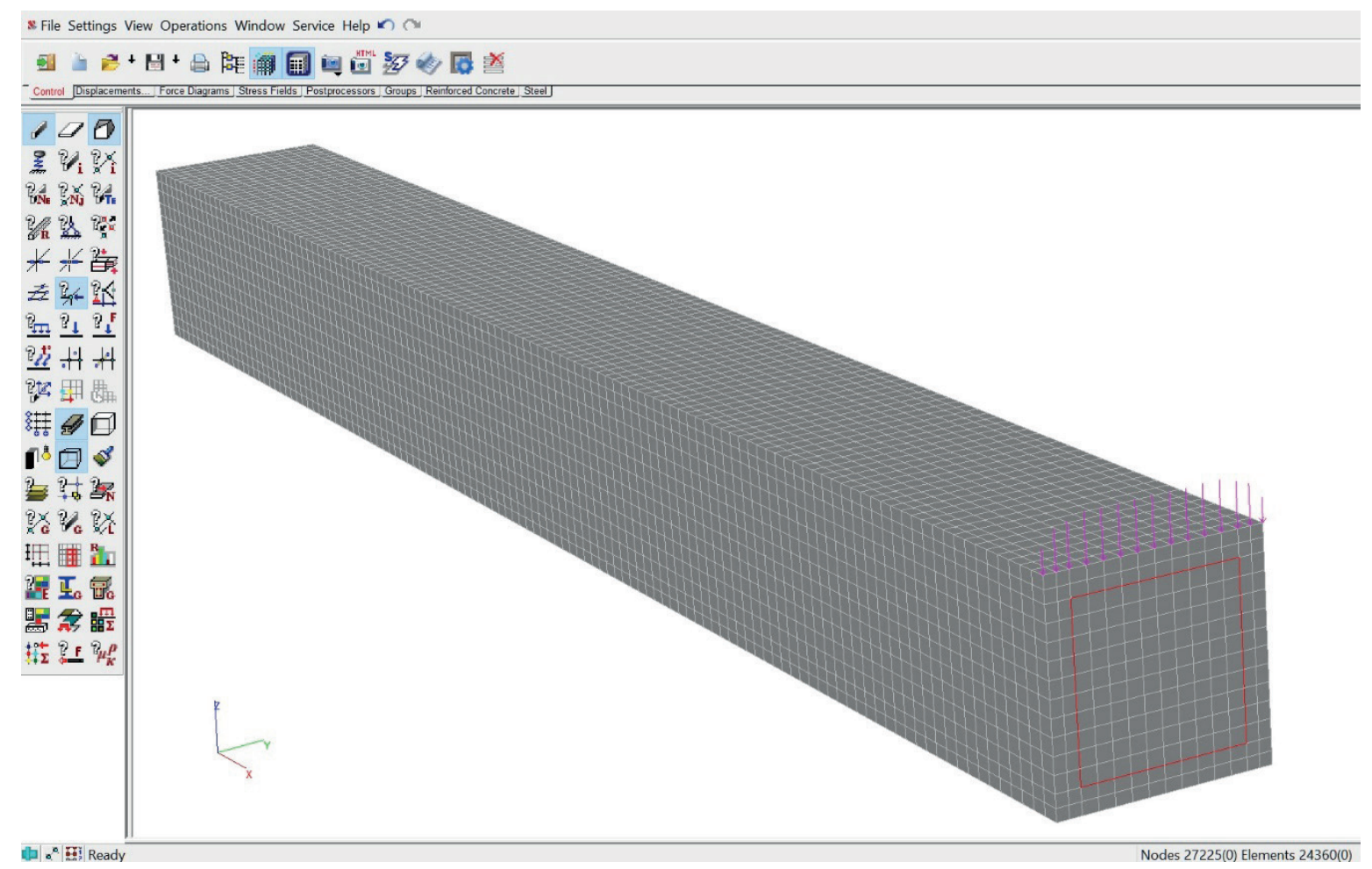

Figure 5 Visualization in SCAD++ of a concrete part assembled from substructures of the $3 D$ model. Reinforcement rebars in the middle section of beam and concentrated load are also given.

to divide section into segments filled with primitives NETWORK in AutoCAD as it is shown in Figure 4.

In Figure 4, four contours represented by different colors in cross-section of a beam are filled by networks on AutoCAD edges using EDGESURF command. The number of splits on two adjacent overlapping edges of a network can be set randomly by assigning values of AutoCAD SURFTAB1 and SURFTAB2 system variables, but these values should be the same in the connected contours. AutoCAD accurately divides the boundary edges of network contours into a specified number of sections of equal length, even if the boundaries are curved. Possible small errors in definition of coordinates by AutoCAD are eliminated in SCAD during the assemblage with the set accuracy. Grids 1,2,3 in Figure 4 have the symmetric sites marked by identical colors. Thus, it is sufficient to form four structures from sub-networks, all the other parts of model are formed in SCAD using the assemblage procedure.

The number of divisions in the cross-section in this example is relatively small, but after setting the number of the $3 \mathrm{D} \mathrm{FE}$ along the axis of the beam, even considering the symmetry, the total number of finite elements was 24360. However, that is far from exceeding the possibilities of system SCAD and can be increased by an order of magnitude.

In a longitudinal direction, the length of the 3D FEs is chosen such that:

The nodes of the $3 \mathrm{D}$ elements along the longitudinal axis of the structure coincide with the nodes of the transverse structural reinforcement, the location of which is shown in Figures 1, 2 and 6;
Dimensions of the 3D finite elements would be close to the topological cube, which gives better accuracy of calculations in the FEM procedures.

In other possible cases of modeling reinforced concrete structures with more irregular placement of the transverse rebars than in this example, additional 3D sub-structures by length can be introduced, which can be grouped into separate parts that are joined during the assembly in SCAD.

Further, each separate sub-network, shown in Figure 4, by dismembering of an initial network by a command AutoCAD, is filled with primitives 3DFACE. The program AutoLISP, forming the text description of each substructure, is started. The resulting sub-structure is then uploaded into SCAD and saved as a separate SCAD project file. Then, it is proceeded to the final assembly of the model from $3 \mathrm{D}$ parts of the structure modeling concrete. The description of this process can be found in the article [18]. Result of an assembly for this example, is presented in Figure 5. For the created model, it is possible to set in SCAD the missing calculation components such as rigidity of 3D elements, units with support, load, before the further final assembly with the substructure modeling the reinforcement.

To simulate the rebar, the AutoCAD LOCK and MASSIVE commands were initially used. To make the nodes of 3D beam (AutoCAD segments) and the nodes of the 3D solid elements coincide, the MASSIVE command is used (Figure 6). Then, after receiving the two files of the AutoCAD drawing with the segments simulating longitudinal and transverse rebars, they are exported to SCAD in DXF format for the subsequent assemblage with substructure (Figure 5), simulating concrete. Each of the two drawings 

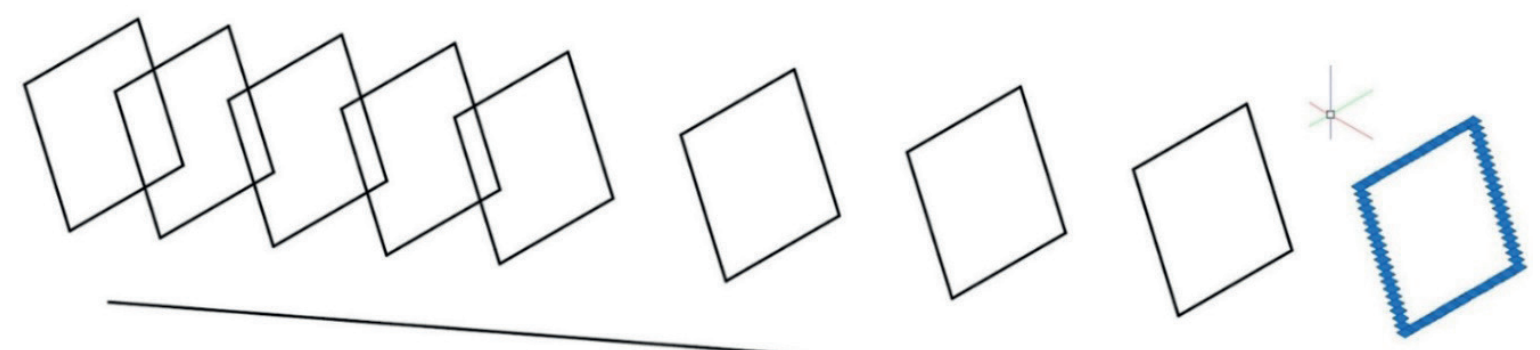

Figure 6 AutoCAD drawing, showing the rebar, longitudinal and transverse, a total of 480 lines. Some of them are marked with grips on the right-hand side in the drawing

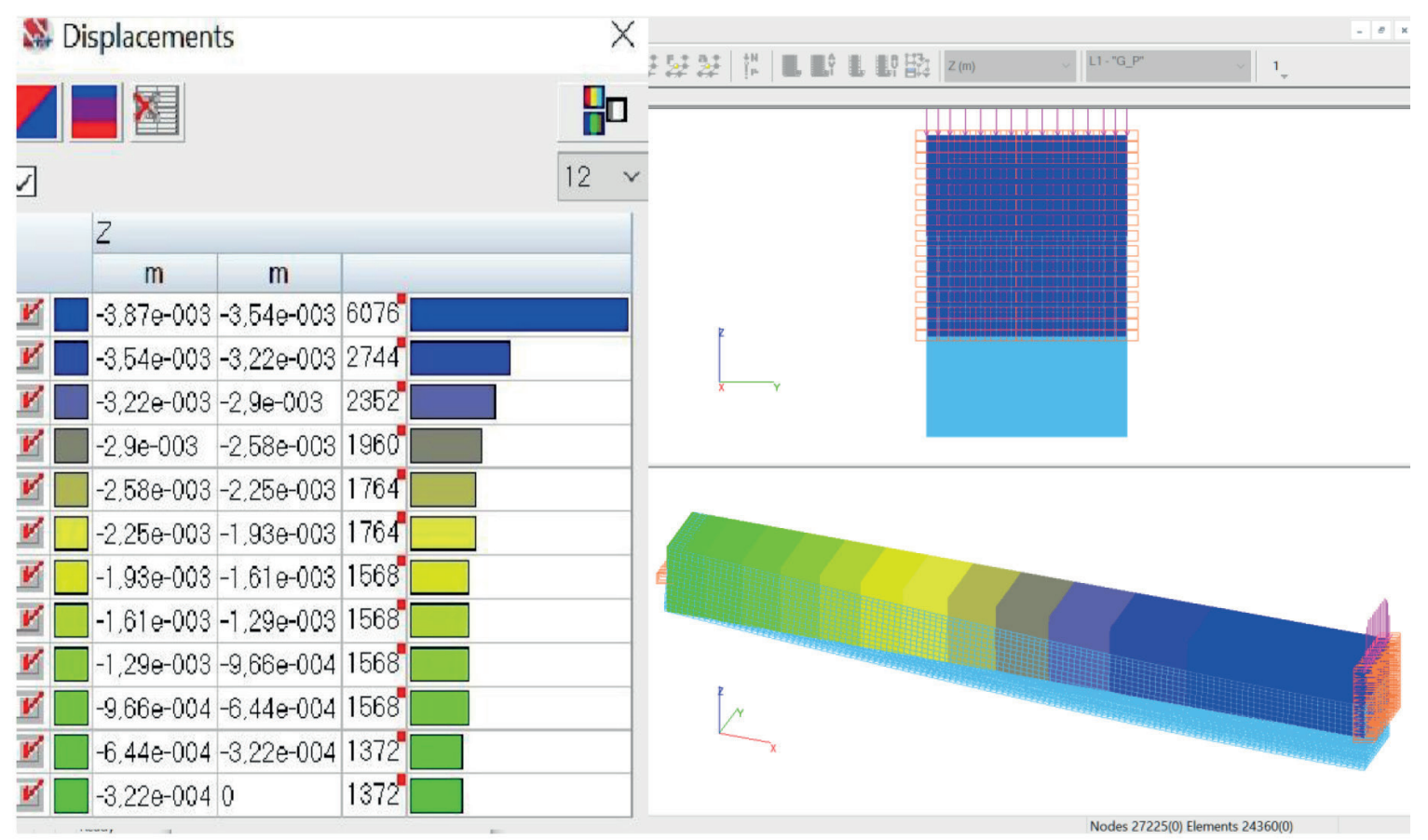

Figure 7Projections of displacements on the $Z$ axis from the self-weight factor and from the load, simulating the concentrated force from Figure 1, the deformed scheme of the 3D calculation concrete + rebars model, in SCAD

of the reinforcement, longitudinal and transverse, in order to facilitate the task of rigidity definition in SCAD, is exported separately, then combined with the model of concrete in the assembly procedures in SCAD.

\section{Results}

Some results of calculation in SCAD for the 3D model of the concrete beam, combined in assemblage with steel rebars, are shown in Figures 7-10.

The maximum value of displacement in the Z-axis direction, obtained in the model calculation, is equal to $-3.87 \mathrm{e}^{-003} \mathrm{~m}$, or $3.87 \mathrm{~mm}$ in the downwards direction. The comparative analysis of difference in deflection values of the beam (calculated numerically) and 3D model gave
$0.05 \mathrm{~mm}$ or $1.25 \%$. The smaller deflection value obtained for the 3D model in comparison to the beam model can be explained by considering the rigidity of the transverse rebar and more accurate distribution of rigidity in the volume of the 3D model compared to the beam theory.

In Figure 7 are also shown the fixed nodes and the axial load (Figure 1), distributed along the transverse line of symmetry in the upper part.

Figures 8 and 9 display the load replacing the concentrated force shown in Figure 1 with calculated force values, considering the symmetry and the unequal spacing between the units, applied to the concrete. The table allows to determine the height of the stretched zone in the critical cross-section along the axis of symmetry of the girder with the maximal internal forces (right-hand end with the applied load). 


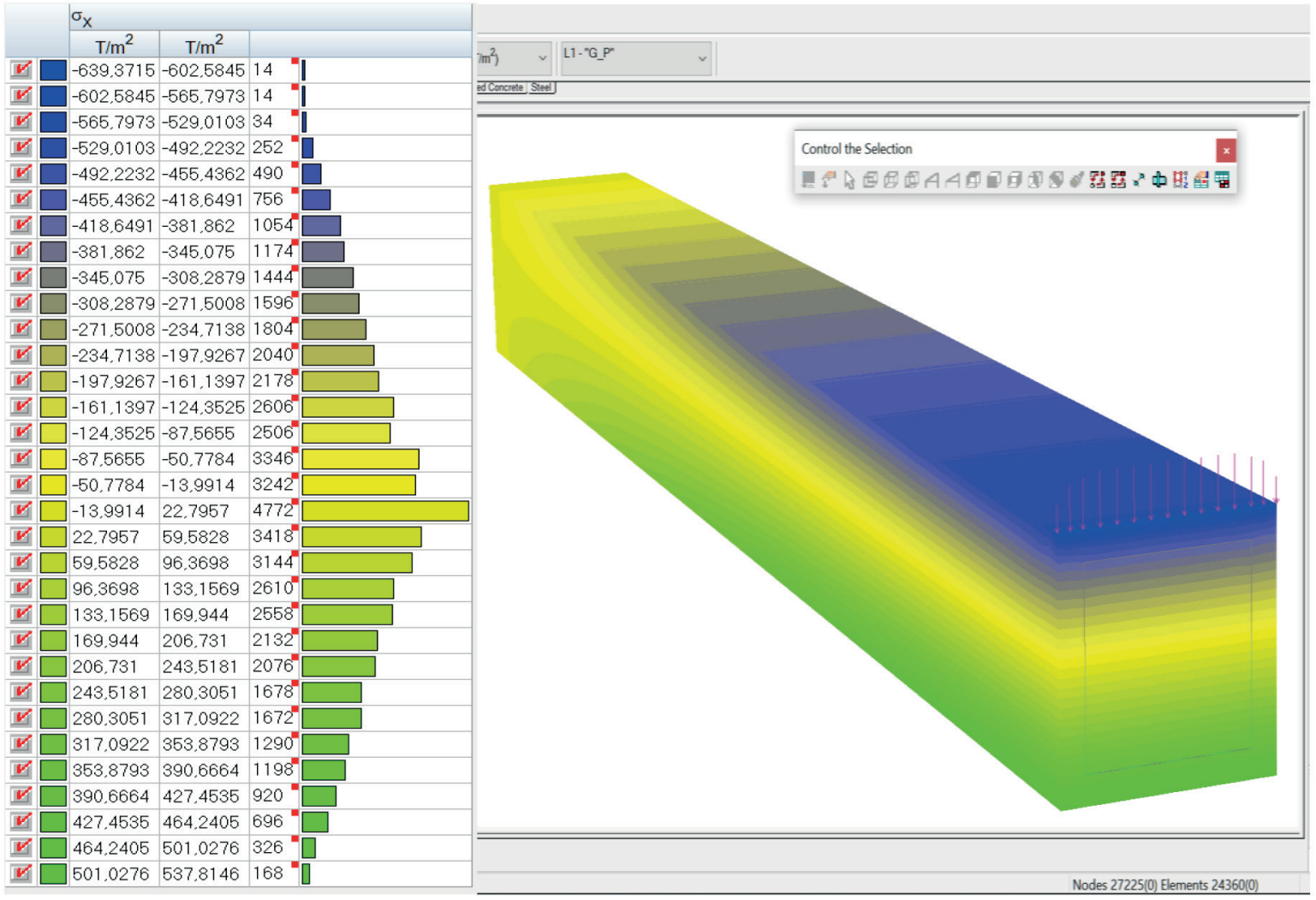

Figure 8 SCAD stress isofields of $\sigma_{x}$ in the direction of the longitudinal axis $X$ on a $3 D$ model
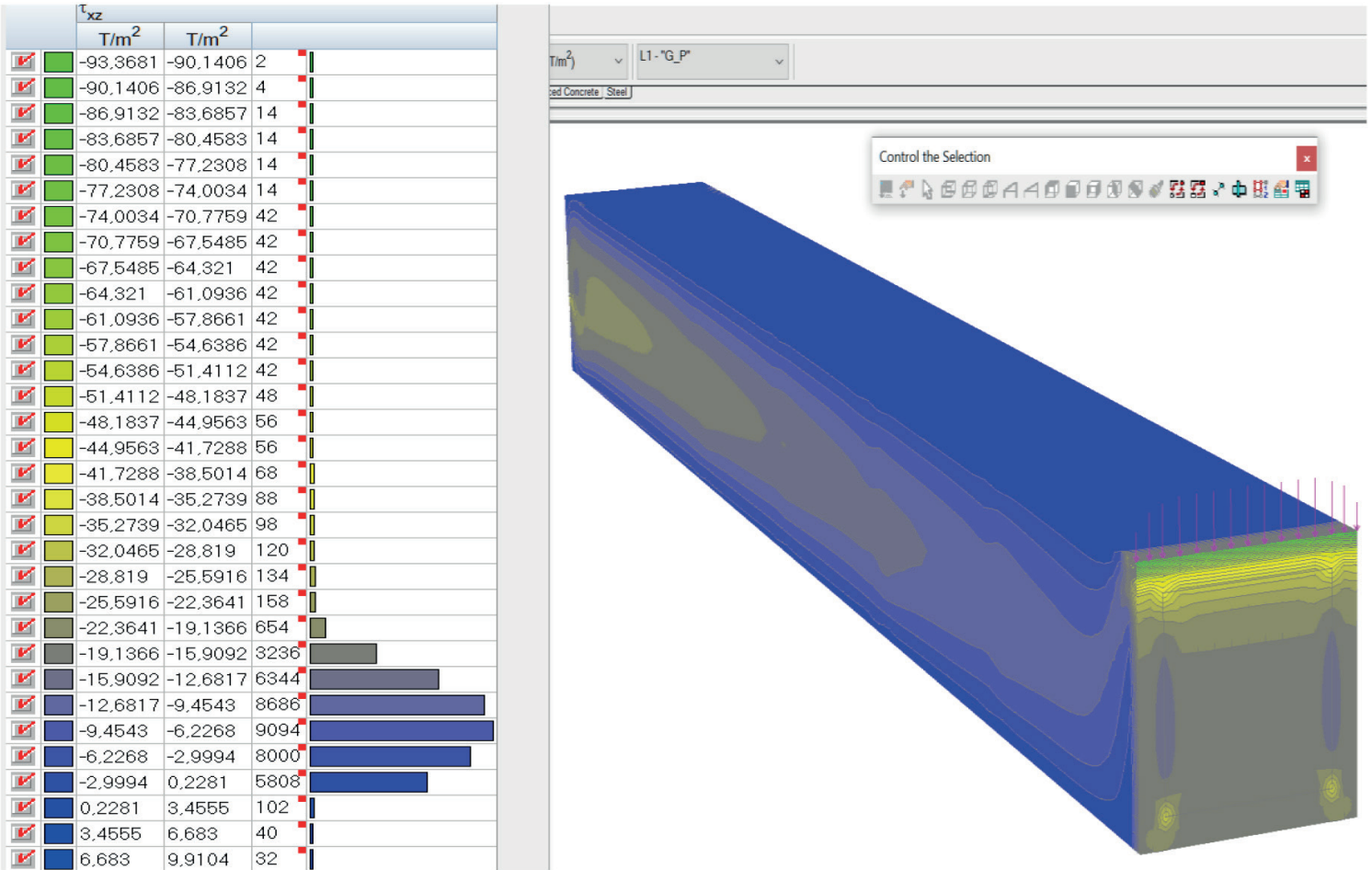

Figure 9 Isofields and isolines of tangential stresses $\tau_{x z}$ in the model

In determining the stress-strain state, the plot of the tangential stress $\tau_{x y}$ distribution can be of interest. In comparison to the theoretical formulas of materials resistance, a significant difference between the $\tau_{x z}$ plot and the picture shown in Figure 9, is obtained, which can be explained by influence of the transverse reinforcement.
After obtaining the precise stress-strain state using the 3D solid FE for the concrete modeling and beam FE for the reinforcement, it is proceeded to the cracks modeling and their opening determination.

Then, it is proceeded to modeling of a crack located in the most loaded cross-section, along the axis of symmetry 

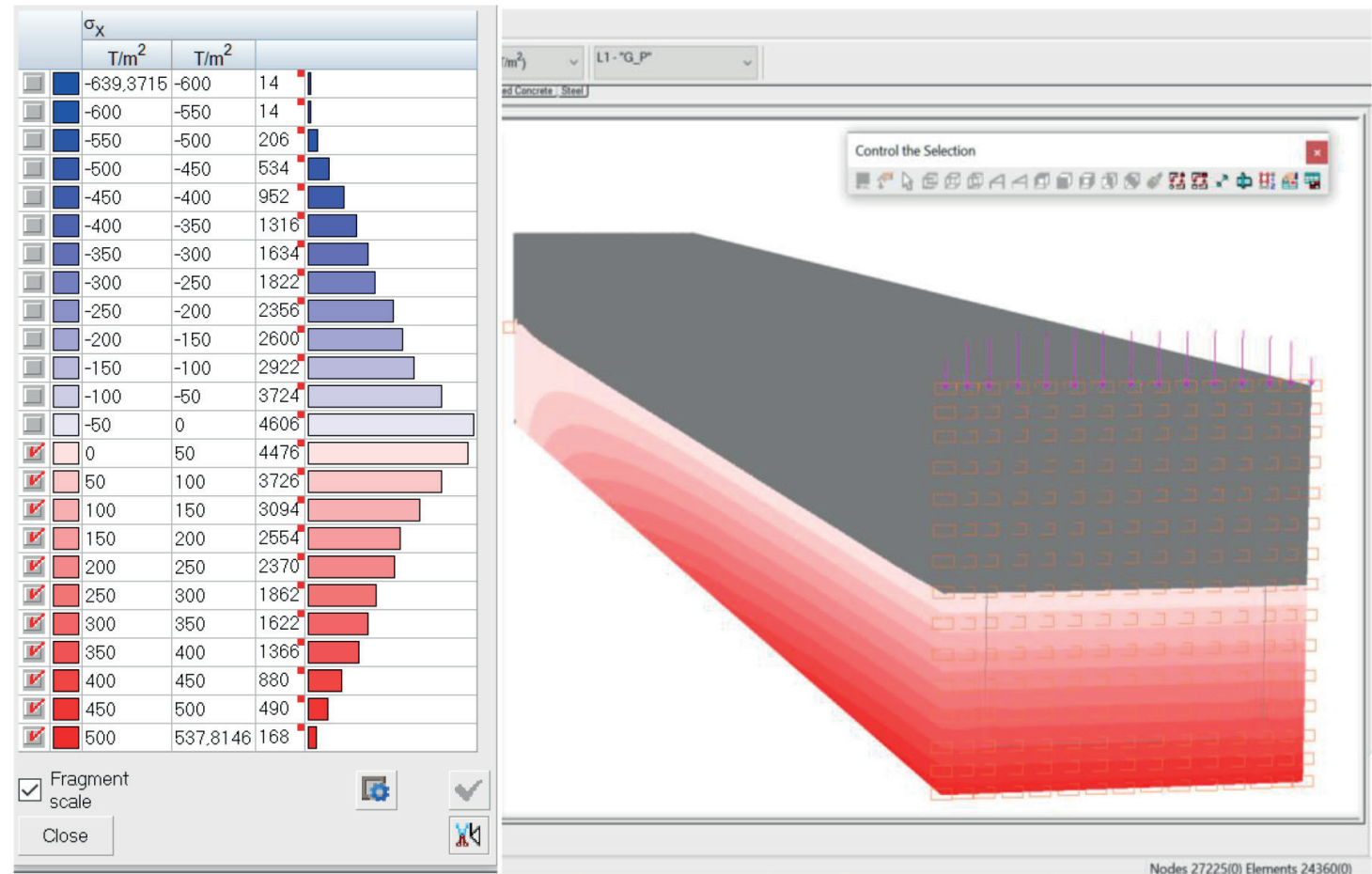

Figure10 Isofields and isolines $\sigma_{x}$ in the structure without crack. Coloring in the compressed and compressed-stretched zone is switched off

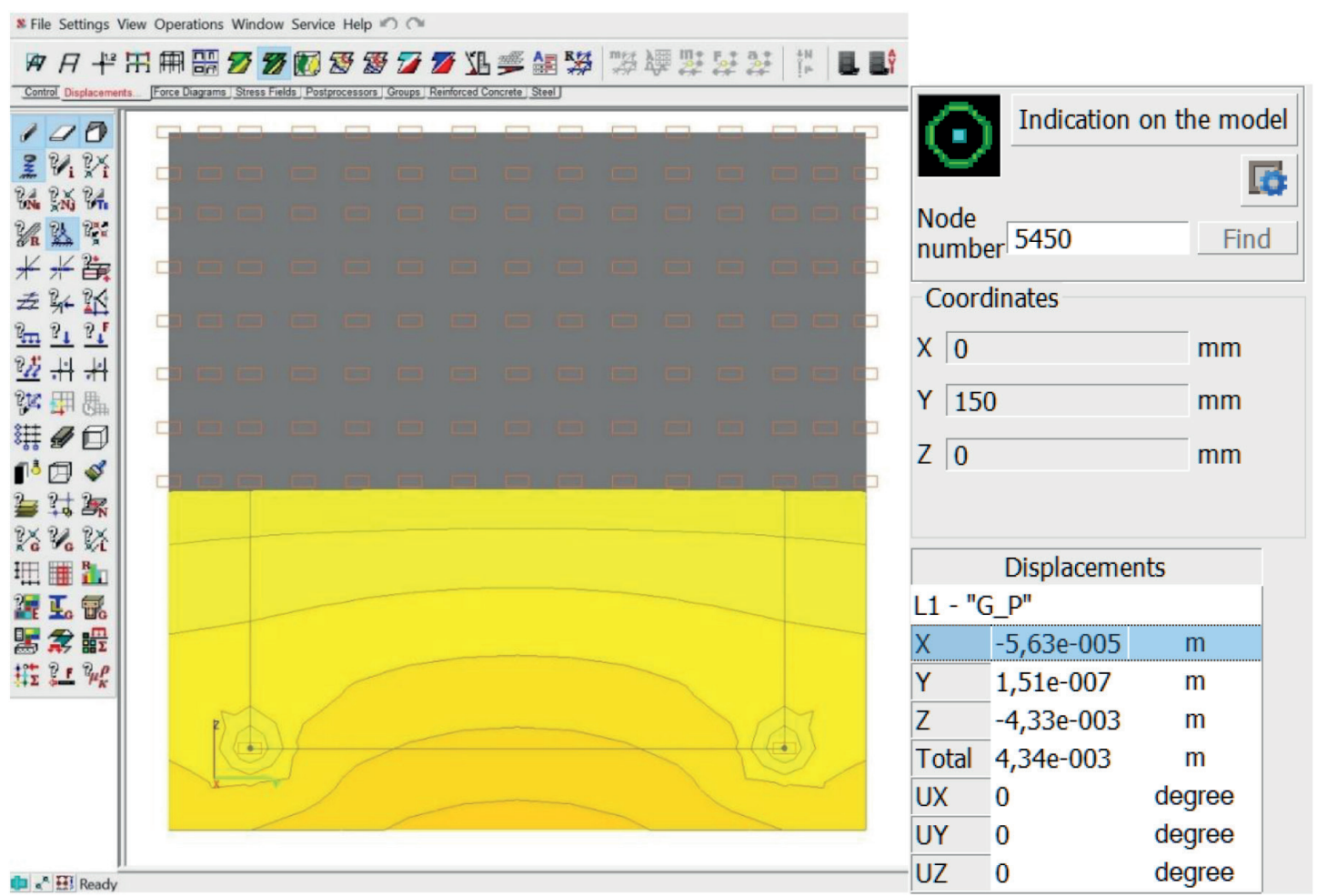

Figure 11 Isofields and isolines of X displacement in cross-section with modeled crack at the first stage of crack development

of the reinforced concrete beam (see Figures 8, 10). The height of a crack development is determined by stress $\sigma$ isopolls preliminary calculated in SCAD++. In Figure 10, obtained based on the calculation results, coloring of the model in a compressed and compressed-strained zone is disabled by means of SCAD++. The stretched zone of the structure, in the right cross section, as it follows from Figure 8, extends to the middle of the section height.

The crack is modeled by removing the longitudinal connections at the right-hand end of the beam, along the symmetry axis, to the height of the lower half of crosssection. In this case, appearance of a crack in this section 


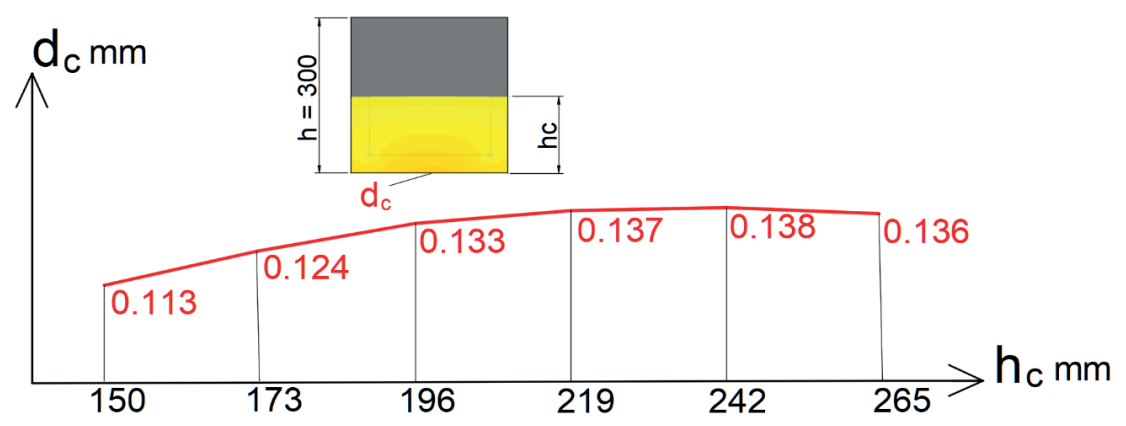

Figure 12 Relation between the maximum crack opening value $d_{c}$ and crack height $h_{c}$
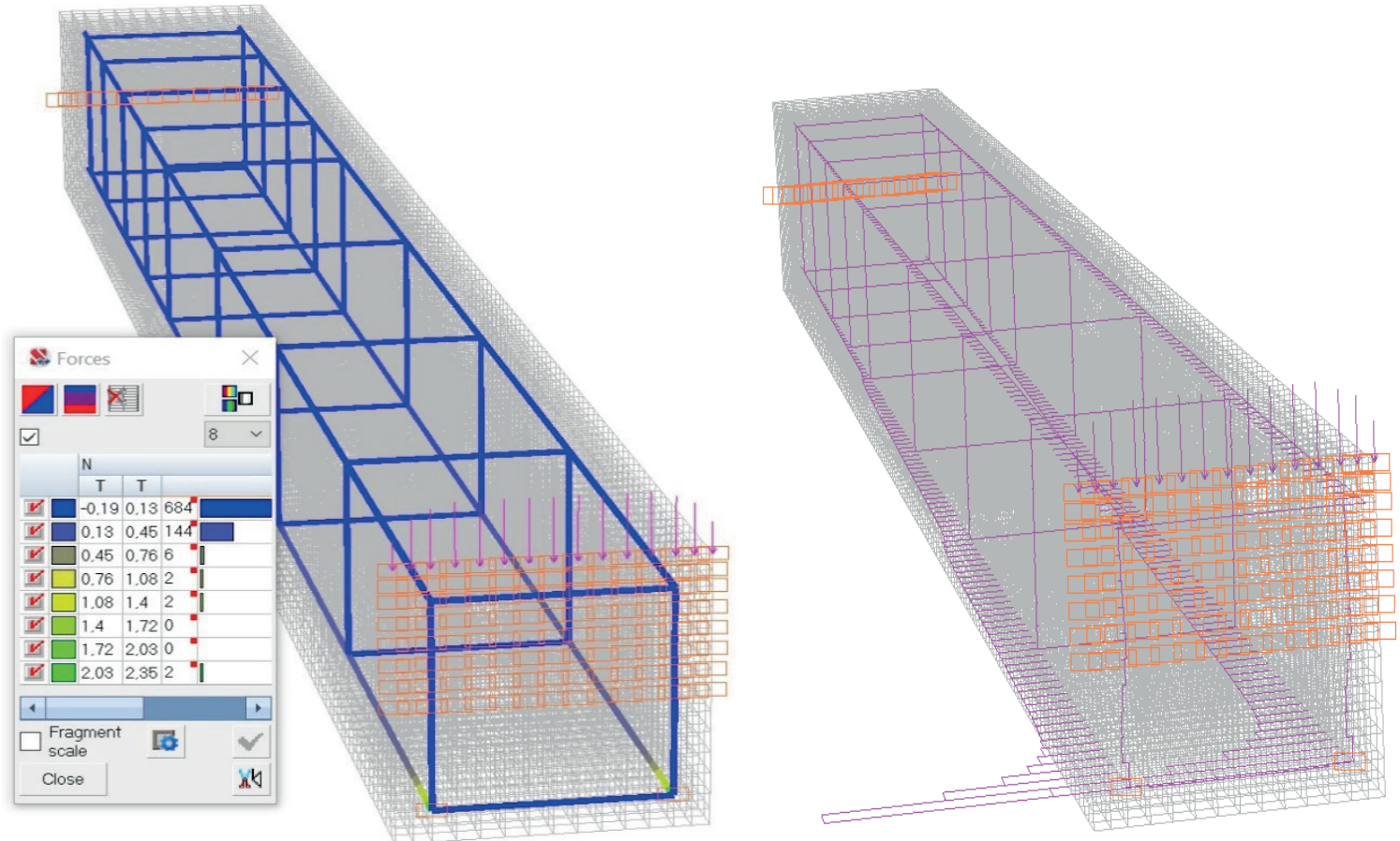

Figure13 Diagrams of longitudinal forces $N$ in the reinforcement rebars of the calculated $R C$ structure with a crack

will lead to displacement of the lower edge to the left, because this accepted section with the crack is located in the symmetry plane. The calculation of this structure is performed.

As a result of the structure calculation, with a modeled crack, the obtained value of maximum deflection - displacement in the Z-axis, has increased by $11.9 \%$, up to $-4.33 \mathrm{~mm}$.

Some other calculation results in $\mathrm{SCAD}++3 \mathrm{D}$ model with a crack are shown in Figures 11 and 12. Longitudinal movements in the section along the axis of symmetry of the beam - opening of the assumed crack, are shown in Figure 11.

Figure 11 also shows regions in the area of the bottom longitudinal rebars, painted grey, with zero displacement along the $\mathrm{X}$ axis due to longitudinal bonds defined in these nodes. The connections in the assumed stretched area are also shown in the form of rectangles above the cross-section. The maximum value of the crack opening as given in the table in Figure 11, is: $0.0563 \times 2=0.113 \mathrm{~mm}$ (multiplied by 2 assuming displacements in the symmetrical part of structure). Six calculations were performed, with longitudinal connections with the assumed crack being removed on one row above at each of the subsequent steps.

The graph of the $d_{c}$ maximum crack opening values variation, obtained in calculation for each stage of crack development, is presented in Figure 12.

The longitudinal forces $\mathrm{N}$ in the reinforcement rebars in the cross section with a crack have increased significantly compared to the calculated values obtained in calculation of the beam without a crack. The N-plots in rebar are shown in two views in Figure13 with the table of values N, also the fixation points are indicated.

It should be noted that the location of cracks in the proposed 3D model of reinforced concrete structures, their length and direction of development, require additional theoretical and experimental justification. Cracks can also be simulated by dividing in $\mathrm{SCAD}++$ the neighboring bulk finite elements by their contact boundaries. 
The two models' calculations results were compared by the crack opening values: $0.388 \mathrm{~mm}$ according to the standard method and its maximum value $0.138 \mathrm{~mm}$ obtained from the 3D model calculation.

Results of the modeling were compared to results obtained by the method established in [22], which is based on stochastic and probabilistic approaches for the characteristics of reinforcement and concrete and is confirmed by extensive practical tests [23-24]. The characteristics used in the calculations with $95 \%$ probability will not exceed the characteristics in real constructions. Safety factors are applied. Thus, this technique provides a guarantee that the results obtained from it will not exceed the critical values included in the SP [22]. According to the standards for this type of construction and operating conditions, the crack opening value should not exceed 0.4 mm [22]. The crack growth to a compressed zone (opening width $0.1126 \mathrm{~mm}$ ) and then to the moment when the crack stopped $(0.138 \mathrm{~mm})$, is simulated. Multiple cracks were modeled, at each stage, the crack opening value was fixed and the most dangerous crack was selected (Figure 12). At the maximum length of the crack, the opening value was $0.138 \mathrm{~mm}$. This corresponds to the criterion defined by standards and is less than those obtained using the method mentioned above [20-22].

The results obtained are less than those calculated according to the standard method, possibly due to the fact that the model took into account the volume work of concrete, longitudinal reinforcement in the compressed and stretched part of the structure, transverse reinforcement.

Results of the two models' calculations are compared according to the crack opening values: $0.388 \mathrm{~mm}$ according to the standard method and $0.1126 \mathrm{~mm}$ obtained from the 3D model calculation. These results showed that the obtained value of the crack opening is more than 3 times less than calculated according to the norms, which may be due to the fact that the model that was built took into account the volume action of concrete, longitudinal reinforcement in the compressed and stretched part of the structure, transverse reinforcement.

\section{Conclusions}

Result of the work, presented in this article, is development of methods for formation of the 3D finite element models of reinforced concrete structures with use of the bulk finite elements for the modeling of concrete and rod elements, modeling rebar, allowing strength calculation of reinforced concrete beams, taking into account crack opening. This applies not only to beam structures, but to the reinforced concrete structures almost of any shape, as well. The proposed method allows modeling cracks in concrete and obtaining the values of crack opening considering the work of longitudinal reinforcement located in a stretched and compressed zone of the structure, transverse reinforcement, which cannot be done using the existing standards. The stress-strain state parameters, obtained by the precise model, allow optimization reinforcement parameters, analyze and consider stress concentrators with possible reinforcement and reinforcement of non-standard cross-sections. Developed program, applied in this article, can be also applied into another FEM software supporting the corresponding file exchange formats. It allows to optimize as much as possible the process of modeling of the massive reinforced concrete structures and thus to reduce time costs.

\section{References}

[1] PERELMUTHER, M. A., POPOK, K. V., SKORUK, L. N. Calculation of the width of disclosure of normal cracks under SP63.13330.2012 ocncrete and reinforced concrete (in Russian). Vol. 1. 2014, p. 21-22.

[2] KARPILOVSKIY, V. S., KRIKSUNOV, E. Z., MALYARENKO, A. A., FIALKO, S. Y., PERELMUTER, A. V., PERELMUTER, M. A. SCAD Office. Ver. 21. Computer complex SCAD++ / Vychislitelnyy kompleks $S C A D++$ (in Russian). Izdatelstvo SKAD SOFT, Izdatelskiydom ASV, 2015.

[3] FIALKO, S., KARPILOVSKYI, V. Multithreaded parallelization of the finite element method algorithms for solving physically nonlinear problems. In: Federated Conference on Computer Science and Information Systems: proceedings.2018. Vol. 15. p. 311-318.

[4] FIALKO, S., KARPILOVSKYI, V. Triangular and quadrilateral flat shell finite elements for nonlinear analysis of thinwalled reinforced concrete structures in SCAD software. In PIETRASZKIEWICZ, W., WITKOWSKI, W. (eds.) Shell structures: theory and applications [online]. Vol. 4. London, New York: CRC Press Taylor \& Francis Group,2017, p. 367-370. eISBN 9781315166605. Available from: https://doi.org/10.1201/9781315166605

[5] 11th international conference Shell structures: theory and applications SSTA 2017: proceedings. CRC Press, 2017. ISBN 978-1138050457.

[6] GAVRILENKO, I. S., GIRENKO, S. V., PERElmuTER, A. V., PERElMUTER, M. A., YURCHENKO, V. V. Load-bearing capacity as an interactive analysis tool in SCAD Office. In: METNET Seminar 2017 in Cottbus: proceedings. 2018. p. 112-127.

[7] NAZARENKO, S. N., GRUDCINA, G. A. Methods of generation of calculation models of structures with monolithic ceiling panels of an arbitrary form (in Russian). Design Bureau. 2016,12(125), p. 18-23. 
[8] FIALKO, S., KARPILOVSKYI, V. Spatial thin-walled reinforced concrete structures taking into account physical nonlinearity in SCAD software. Rod finite element. In: 13th International Conference Modern building materials, structures and techniques: proceedings.2020.p. 728-735.

[9] NUZHDIN, L. V., MIKHAYLOV, V. S., VOSKRESENSKIY, M. N. Methods for subsoil modeling under dynamic impacts and multicomponent damping in SCAD FEA software with geophysical monitoring.Journal of Physics: Conference Series [online]. 2020,1425, 012096. ISSN 1742-6588.Available from: https://doi.org/10.1088/1742-6596/1425/1/012096

[10] FIALKO, S. Y. Dynamic analysis of the elasto-plastic behaviour of buildings and structures in the SCAD++ software package. Journal of Physics: Conference Series [online]. 2020,1425, 012041. ISSN 1742-6588. Available from: https://doi.org/10.1088/1742-6596/1425/1/012041

[11] FIALKO, S., KARPILOVSKYI, V. Time history analysis formulation in SCAD FEA software. Journal of Measurements in Engineering[online].2018, 6(4), p. 173-180. ISSN 2335-2124, eISSN 2424-4635. Available from: https://doi.org/10.21595/ jme.2018.20408

[12] GRUDCINA, G. A., SOKOLOVA, I. I., BATURKIN, D. A. TUN TUN, U. Methods of graphic information transmission for modeling of complex transport infrastructure structures operation using CAD systems. Quality. Innovations. Education. 2017, p. 32-37.

[13] BATURKIN, D. A., GRUDCINA, G. A., REZNIKOVA, E. R. Methods of formation and transfer of graphic information for modeling of objects of a transport infrastructure. Priority directions of science development in the modern world. In: Collection of articles on the materials of the international scientific-practical conference: proceedings. Part 1. 2019. p. 89-93.

[14] SEMENOV, A. A., KILDIBAEV, R. S. Integration of software complexes MIDAS GTS NX and SCAD 21.1 for the solution of interdisciplinary design problems. Industrial and Civil Construction. 2016, 5, p. 72-75.

[15] KUKUSHKIN, I. S., LYUBIMOV, I. Y. Ways to automate the design of supporting structures for equipment using communication technology: SMART 3D - Tekla Structures - SCAD Office. International Journal for Computational Civil and Structural Engineering. 2015, 11(3), p. 126-132. ISSN 2587-9618, eISSN 2588-0195.

[16] KUKUSHKIN, I. S. Implementation of Bilateral Communication between Software Complexes Tekla Structures and SCAD Office v.21.Industrial and Civil Construction. 2014, 9, p. 63-65.

[17] MANGUSHEV, P. A., SAKHAROV, I. I., KONYUSHKOV, V. V., LANKO, S. V. Comparative analysis of numerical modeling of "building-basis" system in SCAD and PLAXIS software packages. Vestnik Civil Engineers. 2010, 3, p. 96-101.

[18] NAZARENKO, S. Automation of creation of volume models for strength calculation in SCAD by means of AutoCAD AutoLISP (in Russian). CAD and Graphics [online]. 2015,6, p. 90-94. Available from: https://sapr.ru/article/24935.

[19] NAZARENKO, S. Automation of strength calculations in SCAD shells - models created in AutoCAD (in Russian). CAD and Graphics [online]. 2010, 2, p. 69-70.Available from: https://sapr.ru/article/21196

[20] Methodical manual calculation of reinforced concrete structures without prestressed reinforcement. NIISF RAASSN. Moscow, 2015.

[21] SP.63.13330.2012. Standard. Concrete and reinforced concrete structures. General provisions. Updated edition of SNiP 52-01-2003 (approved by Order of Ministry of Regional Development of Russia dated 29.12.2011 N 635/8).

[22] Manual for the design of concrete and reinforced concrete structures from heavy concrete without prestressed reinforcement (to SP 52-101-2003), 2005, p. 155.

[23] GOST 24452-80 Concrete. Methods for determination of prismatic strength, modulus of elasticity and Poisson's coefficient.

[24] GOST 26633-91 Concretes heavy and fine-grained. Technical specifications (as amended N 1, 2). 